\title{
To be Supportive or to Care For
}

Stina Thorstensson and Anette Ekström*

School of Health and Learning, University of Skövde, Skövde, Sweden.

*Corresponding author: Anette Ekström RNM, PhD, Associate Professor, Head of Reproductive, Perinatal and Sexual Health, School of Health and Learning, University of Skövde, Skövde, Sweden, Tel: +46 5004484 14; Fax +46 5004484 99; E-mail: anette.ekstrom@his.se

Received date: November 06, 2014, Accepted date: November 13, 2014, Publication date: November 18, 2014

Copyright: (c) 2014 Thorstensson S, et al. This is an open-access article distributedunder the terms of the Creative Commons Attribution License, which permits unrestricted use, distribution, and reproduction in any medium, provided the original author and source are credited.

\section{Editorial}

Support is described as an interactive process that affects wellbeing and health of the individual and it consist of emotional, appraisal, informative and practical acts [1]. Support is linked to social roles and the attachment process [2] which will affect the individual ability both to interact with other people but also to trust other people [3]. Both the capability to provide (i.e. provider) and the capability to receive (i.e. recipient) support are affected by the persons' age, experience and the social environment $[1,2]$. However, the concept of support in relation to the concept of care needs further exploration [4]. There could be a difference between the verb to "act supportive" and to "care for" as these verbs are etymologically different $[5,6]$. To act supportive could etymologically be understood as the provider having "trust in the capacity" of the recipient expecting that the recipient will "take charge". While to "care for" could etymologically be understood as the provider expecting to "be responsible for" and the recipient to be "taken care of" $[5,6]$. This would mean that offering support require that the provider is "more passive" while the recipient is "more active" This is in contrast with to care for which will require that the provider is "responsible for" that is, the provider is more active and the recipient more passive.

The concept of care is multi-dimensional and has been described as both to "care about" in the sense of having an attitude of being interested in the wellbeing of the other person and to "care for" in the sense of actively perform caring activity [7]. When offering professional support it is likely that professionals do that with an attitude of to "care about", wishing for the wellbeing of the other. While to "care for" may inflict a sense of knowing what is best for the patient as has been described for health professionals [8]. However, having trust in women's capacity to give birth is described as essential for supportive care in childbearing [9-11]. This also could suggest a difference in attitude when acting supportive or when to care for. To act supportive also seem to demand that the provider has trust in the capacity of the recipient. The provider may have an expectation that the recipient will "take charge" meaning that the provider should not do so much apart from provide means for the recipient which will enable or strengthen the recipient to cope with the situation, empowering the recipient. This could be in contrast with to care for when the provider could have an expectation to "be in charge" and to "be responsible for" and the recipient will be "taken care of". Therefore it could be important for health care professionals to consider if it is support or care that is needed within each situation. A person in need of support should not be taken care of but a person in need of care should not be offered only support, these seem to be somewhat different actions.

Langford [3] describe that the emotional part of support is most important for the recipient's perception of support as a basic human need of feeling secure and connected [1]. Professional emotional support could be understood as the part of care described as to "care about" [7]. When midwives meet a wider range of supportive needs for the woman and her partner during labor [12], or when mothers perceive stronger emotional support from health professionals $[13,14]$ could be understood as an attitude of to "care about". Process-oriented training $[13,14]$ with directed training and reflection [15] may have an impact on professionals' ability to "act supportive" overall with an attitude to "care about" as opposed to "care for" [7]. Perhaps a wish to "care for" and actually do something will affect professionals to offer more information than is really supportive in the situation when perhaps emotional support is what the woman and her partner require. Mothers describe being disappointed with care after birth because professionals offer information when mothers need emotional support $[16,17]$.

However it is important to offer support in line with the unique needs of the individual and then all aspects of support may be important [1]. Professional support aims to be empowering, which can be considered as both a process and an outcome [8]. As a process empowerment will strengthen individuals and it is an important aspect of supportive midwifery or nursing care [18]. This empowering process can be described as a partnership where professionals have power with the individual instead of professionals having power over the individual [19]. When professionals as midwives and nurses act empowering they can have a significant impact on the lives and health of many individuals and families [18]. In order to empower individuals it is essential that professional support is sensitive for the individuals' unique needs in the specific situation $[1,18,20]$. Which also mean having the ability to identify if the individual has a need for support or a need for care in the actual situation.

\section{References}

1. Langford C, Bowsher J, Maloney J, Lillis P (1997). Social support: a conceptual analysis. Journal of advanced nursing. 25: 95 - 100.

2. Kahn R, Antonucci T (1980)Convoys of the life Course: Attachment, Roles and Social support. Lifespan development and behavior. New York: Academic P253-86.

3. Cassidy J (1999) The nature of the child's ties. In: Cassidy J, Shaver PR, editors. Handbook of attachment Theory, research and clinical applications. New York: The Guildford Press; 25.

4. Thorstensson S, Ekström A (2012) Support as a Concept and with a Focus on Childbearing. J Nurs Care 1(4):e109.

5. Ernby B (2008) Nordstedtetymologiskaordbok Rotolito, LombardaItalien: Nordstedts Akademiskaförlag

6. Hellqvist E (1980)Svensk Etymologisk Ordbok. Lund Sverige: Liber Läromedel Gleerup.

7. Jecker NS, Self DJ (1990) Separating care and cure: an analysis of historical and contemporary images of nursing and medicine. J Med Philos.16:285-306.

8. Oudshoorn A (2005) Power and Empowerment: critical concepts in the nurse-client relationship. Contemporary Nurse. 20:57-66. 
9. Kennedy HP (2002) The Midwife as an "Instument" of Care. American Journal of Public Health. 92:1759-60.

10. Lundgren I (2004) Releasing and relieving encounters: experiences of pregnancy and childbirth. Scandinavian Journal of Caring Sciences. 18:368-75.

11. Fahy K, Parrat J (2006) Birth Territory: A theory for midwifery practice. Midwifery. 19:45-50.

12. Thorstensson S, EkströmA, Lundgren I, Hertfelt Wahn E (2012) Exploring Professional Support Offered by Midwives during Labour: An Observation and Interview Study Nursing Research and Practice.

13. Blixt I, Mårtensson L, Ekström A (2014) Process-oriented training in breastfeeding for health professionals decreases women's experiences of breastfeeding challenges International Breastfeeding Journal. 9: 15

14. Thorstensson S, Nissen E, Ekström A (2012) Professional Support in Pregnancy Influence Maternal Relation to and Feelings for the Baby after Cesarean Birth; an Intervention Study. J Nurs Care.

15. Thorstensson S, Nissen E, Ekström A (2008) An exploration and description of student midwives' experiences in offering continuous labour support to the woman/couple. Midwifery. 24: 451-9.
16. Razurel C, Bruchon-Schweitzer M, Dupanloup A, Irion O, Epiney M (2011) Stressful events, social support and coping strategies of primiparous women during the postpartum period: a qualitative study. Midwifery. 27:237-42.

17. Ekström A, Widström A-M, Nissen E (2012) Breastfeeding Support from Partners and Grandmothers: Perceptions of Swedish Women. Birth. 30:261-6.

18. Hermansson E, Mårtensson L (2011) Empowerment in the midwifery context - a concept analysis. Midwifery. 27: 811-6.

19. Labonte R (1994) Health promotion and empowerment: reflections on professional practice. Health Education Quarterly. 21:253-68.

20. Bäckström C, Hertfelt-Wahn E, Ekström A (2010) Two sides of breastfeeding support: experiences of women and midwives. International Breastfeeding Journal 5(20) 